\title{
A TGA/DTA-MS investigation on the difference between organic-rich and organic-free mudstones in pyrolysis process
}

\author{
Pengyan Du ${ }^{1}$, JingONG CAI $^{1}{ }^{*}$, HuIdONG LI ${ }^{2}$ \\ ${ }^{1}$ State Key Laboratory of Marine Geology,Tongji University, \\ Shanghai, China(*correspondence:jgcai@tongji.edu.com) \\ ${ }^{2}$ Shanghai Institute of Ceramics, Chinese Academy of \\ Sciences, Shanghai, China
}

The role of water plays on petroleum generation has been proved to be very important. The previous studies mostly focus on the hydrous pyrolysis and characteristics of added water in the process. However, the simulation experiment can't fully represent the real formation. The water and other inorganic and organic products in the real formation should be learned more that it will be useful for further studying the relationship between water and hydrocarbon generation. Thermogravimetric analysis (TGA) and differential thermal analysis (DTA) combined with mass spectrometry (MS) afford the opportunity to identify the types and amounts of the compounds under a continuous heating process. In this work, we use TGA/DTA-MS to investigate the pyrolysis differences of organic-rich $(\mathrm{CN1})$ and organic-free (CW1) mudstones in Dongying Sag and then to find the relationship between $\mathrm{H}_{2} \mathrm{O}, \mathrm{CO}_{2}$ and organic matter. The results showed that the pyrolysis process of $\mathrm{CN} 1$ and $\mathrm{CW} 1$ all can be divided into three stages by the TGA/DTA curves. Sample CW1 released adsorption water and interlayer water, crystalstructural water, carbon dioxide separately in the tree stages. While sample $\mathrm{CN} 1$ generated adsorption water, interlayer water and crystal-structural water, carbon dioxide of both organic and inorganic origin. In addition, the temperature of interlayer water and $\mathrm{CO}_{2} \mathrm{MS}$ peak of $\mathrm{CN} 1$ is higher than CW1 revealed that organic matter may influence the output temperatures of inorganic products. What's more, using the mineral data and MS results could construct the relationship between organic-free mudstones and organic-rich mudstones. The quantitative analysis showed the $\mathrm{CO}_{2}$ content of $\mathrm{CN} 1$ of mineral origin is about $11.78 \%$, and of organic origin is about $6 \%$. There is about $3.63 \%$ of $\mathrm{H}_{2} \mathrm{O}$ released from $\mathrm{CN} 1$ and the adsorption water is about $0.08 \%$, other types of water is about $2.55 \%$ in total. This work is meaningful for further studying the $\mathrm{H}_{2} \mathrm{O}$ content in petroleum source rocks.

Acknowledgment: This work was supported by the National Natural Science Foundation of China (Grant Nos. 41672115, 41972126]; the National Petroleum Major Project of China (Grant No. 2016ZX05006001-003) 